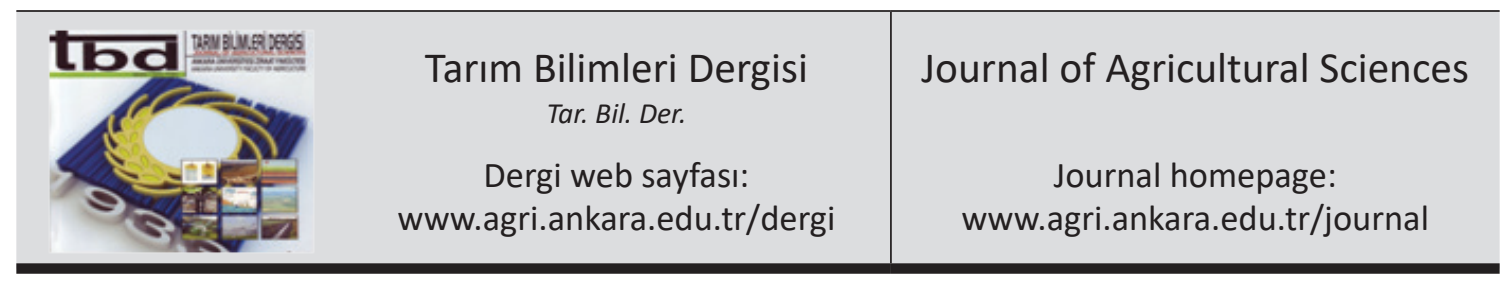

\title{
Effects of Leaf Surface Energy on Pesticidal Performance
}

\author{
Muhammed Cemal TORAMAN ${ }^{\mathrm{a}}$ \\ ${ }^{a}$ Hakkari University Çölemerik Vocational School, Hakkari, TURKEY
}

\author{
ARTICLE INFO \\ Research Article \\ DOI: 10.15832 /ankutbd.382143 \\ Corresponding Author: Muhammed Cemal TORAMAN, E-mail: cemaltoraman@hotmail.com, Tel: +90 (507) 3357377 \\ Received: 22 January 2018, Received in Revised Form: 20 April 2018, Accepted: 25 April 2018
}

\begin{abstract}
Surface energy is widely used in the industry to predict behavior of spray droplets on solid surfaces. The targets of pesticide applications which are used extensively in agricultural production are mainly plant leaf surfaces. Digitization of leaf surfaces to estimate the spread and adhesion of a pesticide application is an important approach in providing descriptive information. In this regards, from intensive agricultural products Triticum aestivum L., Citrus sinensis, Fragaria ananassa, Vitis vinifera L., Cucumis sativus, Capsicum annuum L. culture plants, Elymus repens and Sinapis arvensis from weeds were used to determine surface energy. The leaf surface energies were determined by evaluating the contact angles of the drips while obtained from surface tension and its components from known liquids pure water, diiodomethane and formamide liquids on the surface of the leaves according to five different methods. Wu and Equation of State methods have been found to give more accurate results than other methods. Elymus repens and Triticum aestivum L. plants among the statistically three significant grouped leaves were reduce the spreading and sticking of droplets applied on the leaves by providing a more spherical droplet formation. The Fragaria ananassa leaves have encouraged the higher surface energy that they have the spread of the drips on the leaf surface.
\end{abstract}

Keywords: Contact angle; Diiodomethane; Leaf; Spray; Surface tension; Wu

(C) Ankara Üniversitesi Ziraat Fakültesi

\section{Introduction}

It is predicted that, in spite of the increasing population, the consumption of projections of pesticide use will increase in order to obtain sufficient crops from declining agricultural areas. Researches related to pesticide application have mostly focused on pesticide formulations and the physical properties of liquids and leaves. As a result of the researches, it has been found out that various factors have an effect on the success of applications (spray), these are; epicuticular wax, epidermal cell structure, wax crystals, amount of wax, shape, composition (Wohlfahrt et al 2006;
Puente \& Baur 2011; Massinon \& Lebeau 2012), chemical functional groups on the leaf surface, leaf roughness, leaf hairs, general shape of epidermal cells, cuticle folds, hairs (trichomes) (Wagner et al 2003), nanostructure of wax crystals (Khayet \& Ferna'ndez 2012), enhanced wetting in some plant species with open trichome pattern caused by capillary action (Holloway 1970), lattice arrangement and structure of molecules (Brewer et al 1991; Wang et al 2014).

It is known that the application of liquid to different leaf surfaces results in different contact angles and spreading levels on the surfaces. This 
happens due to different surface energies produced by the molecular structure in the chemical structure of each leaf. The estimation of a study related to water adhesion is an easy and valuable tool that can be used to quantify the adhesion degree of a particular plant surface (Fernández et al 2014). Various different models have been developed in order to determine the surface energy of an object. Five of the commonly used methods were used in the experiments. The general information on these is briefly as follows.

The surface energy of a solid object is not a quantity that can be measured directly. It is determining the droplet contact angles applied to the solid surface as a function of the surface tension based on the evaluation of Young's equation (Equation 1) according to different models. It is based on the spread of the droplet surface tension on the target according to the size of the surface energy of the solid.

$\gamma_{2}=\gamma_{12}+\gamma_{1} \cos \theta$

It is generally based on the prediction that the surface energy of a solid $\gamma_{2}$ is equal to the sum of the surface tension of the liquid $\gamma_{1}$ and the interfacial tension $\theta$ which is derived from the cosine of the horizontal component of the droplet contact angle on the solid surface $\gamma_{12}$. Contact angle $(\theta)$ is the quantitative measurement of the wetting rate of a solid surface by a liquid. The other approaches foreseen in line with this basic principle are as follows;

According to Zisman, the surface energy of the solid matter is determined by the droplets' contact angles formed on the surface of the applied liquids. Here, the values corresponding to the cosine of the contact angle data $(\cos \theta)$ are drawn in the form of surface tension of the liquids, and with a contact angle of $0^{\circ}$, the highest surface tension value for the liquid which will completely wet the solid is obtained by being arranged for $\cos \theta=1\left(\theta=0^{\circ}\right)$. This is considered equal to the surface energy of the solid (Zisman 1964).

In the Equation of State method, in order to calculate the surface free energy with the contact angle, the second unknown variable must be determined (Moy \& Neumann 1987; Li \& Neumann 1992).

$\gamma_{12}=\gamma_{1}+\gamma_{2}-2 \sqrt{\gamma_{1} \cdot \gamma_{2}} \cdot e^{-\beta\left(\gamma_{1}-\gamma_{2}\right)^{2}}$

$\cos \theta=-1+2 \sqrt{\frac{\gamma_{2}}{\gamma_{1}}} \cdot e^{-\beta\left(\gamma_{1}-\gamma_{2}\right)^{2}}$

The polar and dispersive parts of the surface tension are not taken into consideration. Experimentally, the value of $0.0001247\left(\mathrm{~m}^{2} \mathrm{~mJ}^{-1}\right)^{2}$ is determined for the constant $\beta$ (Hansen 2004; Krüss 2017).

OWRK and Fowkes models are based on the assumption of the sum of interfacial interactions dependent on the polar $\left({ }^{\mathrm{p}}\right)$ and dispersive $\left({ }^{\mathrm{d}}\right)$ properties of the solid measured with the measurement liquid (Fowkes 1964; Owens \& Wendt 1969; Kaelble 1970; Rabel 1971).

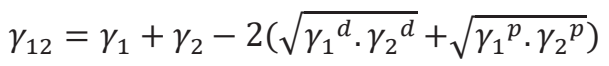

Since $\gamma_{2}{ }^{p}$ and $\gamma_{2}{ }^{d}$ are not known in the Equations 4 and 5, two liquids, one of which is polar and the other is dispersive, should be used for the solution. Water, formamide polar liquids, and diiodomethane are the most commonly used dispersive liquids.

Wu's method involves the approach that the use of the harmonic mean of the polar and dispersive components in determining the surface energy yields more reliable results compared to the geometric mean used in OWRK \& Fowkes methods.

$\gamma_{12}=\gamma_{1}+\gamma_{2}-4\left(\frac{{\gamma_{1}}^{d} \cdot \gamma_{2}{ }^{d}}{{\gamma_{1}}^{d}+\gamma_{2}{ }^{d}}+\frac{\gamma_{1}^{p} \cdot \gamma_{2}^{p}}{\gamma_{1}^{p}+\gamma_{2}^{p}}\right)$

Wu's method is mostly used for free surface energy calculations for objects with low surface free energy (up to 30-40 $\mathrm{mJ} \mathrm{m}^{-2}$ ) (Wu 1973).

In acid-based methods, the polar component is divided into acid and base components, and the Equation is written as:

$\gamma_{12}=\gamma_{1}+\gamma_{2}-2\left(\sqrt{\gamma_{1}^{d} \cdot \gamma_{2}^{d}}+\sqrt{\gamma_{1}^{+} \cdot \gamma_{2}{ }^{-}}+\sqrt{\gamma_{1}^{-} \cdot \gamma_{2}{ }^{+}}\right)$ 
In order to solve the Equation, at least three liquids with known properties are required. One of them is a fluid with dispersive properties (e.g., diiodomethane), the other is a bipolar fluid with polar properties (e.g., water, formamide) (Krüss 2017).

In the study, it is aimed to determine the reactions of some of the conventional products used in intensive farming against the spray applied in the agricultural struggle, as meaningful quantitative relations. Therefore, alteration of the droplets applied to the leaf surfaces based on the leaf types will be determined in terms of energy. On the other hand, the possibility of developing alternative approaches for the preparation of effective pesticide tank mixes arranged based on plant species has been examined by comparing the obtained data with the surface tensions of the application liquid.

\section{Material and Methods}

In order to determine the impacts of surface energy on pesticide applications, plants that are commonly produced and frequently exposed to pesticide applications were used in the experiments. Triticum aestivum L., Citrus sinensis, Fragaria ananassa, Vitis vinifera L., Cucumis sativus, Capsicum annum L. cultivated plants Elymus repens and Sinapis arvensis weeds obtained from Cukurova University research (production) farms were placed in a pot to maintain the living features, and the leaves were cut and the necessary measurements were made in due course.

Pure water, $99 \%$ pure formamide and diiodomethane in the Middle East Technical University Central Laboratories are used in the contact angle, surface tension, interfacial tension and surface energy measurements that provide information on the surface properties affecting the liquid such as spread, wettability, absorption, surface tension, etc. In order not to affect the properties of other liquids, operations were carried out by drawing each liquid into three different syringes. "Sessile drop technique", which is the most commonly used technique on flat surfaces for contact angle measurements, was used. Since the shape and contact angle of droplets on solid surfaces are dependent on the liquid's effect on the surface tension, liquid surface tensions should be known in order to determine the surface energies of objects. For this, the optical contact angle and surface tension measurement device produced by KSV firm Attention Theta (Goniometer) was used, which analyzes the droplet shape based on time by saving the images of the droplet.

The leaves to be measured were separated from the plants from the cross sectional areas by about 1 $\mathrm{cm}^{2}$ by means of scissors, and placed on the sample stage of the device by carefully sticking them onto the glass slide using double sided tape to prevent any deformations on the surface. The sample stage of the device can be easily adjusted forward-backward, up-down and right-left. The syringes, into which liquid was drawn, were attached to the Goniometer, a hanging droplet was formed at the tip of the needle, and was contacted with a leaf surface. Meanwhile, falling of droplet can also be monitored on the screen. Then, the right and left contact angles were started to be measured in real time with the software's detection of the droplet wall. At least five drops of the same liquid were measured and the angles of both sides of the contacting droplets were determined. Asymmetric measurements (when the difference between the angles of both sides were higher than five degrees) were removed from the data. The surface tension given in Table 1, and the contact angles and standard deviation values given in Table 2 and the average contact angles and standard errors obtained on the leaf surfaces that given in Table 3 are obtained in real time by opening the saved measurement images to analyze further through the use of statistical function.

The contact angles on the leaf surfaces, and the surface tension data of the liquid used were calculated in the Goniometer software, in accordance with the guidelines for surface energy calculation methods. The surface energy values of the plant leaves were obtained as in Table 4.

The statistical analyzes were carried out with version 18 of the SPSS package program. Differences between the plant species were evaluated according to Tukey multiple comparison test for 5\% level of significance. 
Table 1- Liquid surface tension parameters

\begin{tabular}{lccccc}
\hline Heavy phase & $\boldsymbol{\gamma}^{\text {tot }}\left(\mathrm{mN} \mathrm{m}^{-1}\right)$ & $\boldsymbol{\gamma}^{d}\left(\mathrm{mN} \mathrm{m^{-1 } )}\right.$ & $\boldsymbol{\gamma}^{p}\left(\mathrm{mNm^{-1 }}\right)$ & $\boldsymbol{\gamma}^{+}\left(\mathrm{mN} \mathrm{m}^{-1}\right)$ & $\boldsymbol{\gamma}^{-}\left(\mathrm{mN} \mathrm{m} \mathrm{m}^{-1}\right)$ \\
\hline Water & 72.8 & 21.8 & 51.0 & 25.5 & 25.5 \\
Diiodomethane & 50.8 & 50.8 & 0.0 & 0.0 & 0.0 \\
Formamide & 58.0 & 39.0 & 19.0 & 2.3 & 39.6 \\
\hline
\end{tabular}

Table 2- The contact angles and standard deviations of the liquids formed on the surfaces of the leaves

\begin{tabular}{clrrrrrr}
\hline Method & Crop & Water & SD & Diiodomethane & SD & Formamide & SD \\
\hline & Citrus sinensis & $100.2^{\mathrm{b}}$ & 5.9 & $62.2^{\mathrm{a}}$ & 7.6 & $69.2^{\mathrm{ab}}$ & 5.6 \\
& Triticum aestivum L. & $126.4^{\mathrm{c}}$ & 6.1 & $93.2^{\mathrm{b}}$ & 6.9 & $144.8^{\mathrm{c}}$ & 2.5 \\
& Fragaria ananassa & $85.8^{\mathrm{b}}$ & 6.3 & $56.2^{\mathrm{a}}$ & 11.7 & $59.8^{\mathrm{a}}$ & 6.3 \\
Contact angle & Vitis vinifera $\mathrm{L}$. & $109.0^{\mathrm{c}}$ & 2.5 & $67.8^{\mathrm{a}}$ & 6.8 & $90.6^{\mathrm{b}}$ & 10.2 \\
$\left(\theta^{\circ}\right)$ & Cucumis sativus & $94.6^{\mathrm{b}}$ & 8.4 & $58.4^{\mathrm{a}}$ & 10.6 & $56.6^{\mathrm{a}}$ & 6.0 \\
& Capsicum annumm $\mathrm{L}$. & $87.0^{\mathrm{b}}$ & 11.7 & $53.8^{\mathrm{a}}$ & 6.1 & $80.9^{\mathrm{b}}$ & 7.9 \\
& Elymus repens & $150.2^{\mathrm{c}}$ & 8.0 & $97.8^{\mathrm{b}}$ & 8.5 & $138.2^{\mathrm{c}}$ & 3.2 \\
& Sinapis arvensis & $98.2^{\mathrm{b}}$ & 5.2 & $61.0^{\mathrm{a}}$ & 2.6 & $74.0^{\mathrm{ab}}$ & 1.2 \\
\hline
\end{tabular}

*, the difference between the same letters is insignificant at the $\mathrm{P}<0.05$ level

Table 3- The contact angles and standard errors that form on the leaf surfaces

\begin{tabular}{lcc}
\hline Crop & Mean $\left(\theta^{\circ}\right)$ & $S E$ \\
\hline Citrus sinensis & $77.2^{\mathrm{ab}}$ & 4.6 \\
Triticum aestivum $\mathrm{L}$. & $121.5^{\mathrm{c}}$ & 5.9 \\
Fragaria ananassa & $67.3^{\mathrm{a}}$ & 4.1 \\
Vitis vinifera $\mathrm{L}$. & $89.1^{\mathrm{b}}$ & 4.8 \\
Cucumis sativus & $69.9^{\mathrm{ab}}$ & 5.1 \\
Capsicum annumm $\mathrm{L}$. & $71.6^{\mathrm{ab}}$ & 4.2 \\
Elymus repens & $128.8^{\mathrm{c}}$ & 6.2 \\
Sinapis arvensis & $78.5^{\mathrm{ab}}$ & 4.2 \\
\hline
\end{tabular}

*, the difference between the same letters is insignificant at the $\mathrm{P}<0.05$ level

\section{Results and Discussion}

\subsection{Contact angle measurements}

The surface energy of an object depends on its ability to meet the requirements of the particular model selected for the analysis of the liquids that are deemed appropriate for use. In order to obtain more consistent results and make comparisons, the most preferred ones in the literature were selected from among the liquids meeting the specified conditions. The liquids used in the experiments and some of their properties are given in Table 1. It can be observed that water and formamide liquids have both dispersive and polar properties, and also charge values. It can be understood that the diiodomethan liquid is of a dispersive nature.

When the aim is to characterize the objects through the components of surface energy, conversion of contact angle data to surface energy values is utilized. The contact angles obtained from the leaf surfaces are given in Table 2 and Table 3. Fragaria ananassa when the lowest contact angle was obtained from the leaves, Cucumis Sativus, Capsicum annuum L, Citrus sinensis ve Sinapis arvensis the leaf surfaces formed higher contact angles. While the leaves Triticum aestivum $\mathrm{L}$. and Elymus repens formed the surfaces that produced the highest contact angles, the leaves Vitis vinifera L. produced contact angles at intermediate values.

When the contact angles are examined based on the liquids, in Table 1, inversely proportional contact angles were obtained from the liquids with high dispersive components. While the diiodomethane liquid formed the smallest contact angle on the leaf surfaces, greater contact values proportional to the dispersive value were obtained from the formamide liquid. It has been determined that the 
Table 4- Liquid surface energy parameters

\begin{tabular}{|c|c|c|c|c|c|c|}
\hline Crop & Method & $\boldsymbol{\gamma}^{\text {tot }}\left(m N m^{-1}\right)$ & $\boldsymbol{\gamma}^{d}\left(m N m^{-1}\right)$ & $\boldsymbol{\gamma}^{p}\left(m N m^{-1}\right)$ & $\gamma^{+}$ & $\gamma^{-}$ \\
\hline \multirow{5}{*}{ Citrus sinensis } & Acid-Base & 27.721 & 27.745 & -0.024 & 1.088 & -0.011 \\
\hline & Equation of State & 29.006 & 29.006 & & & \\
\hline & OWRK/Fowkes & 30.039 & 29.312 & 0.727 & & \\
\hline & $\mathrm{Wu}$ & 33.017 & 30.190 & 2.827 & & \\
\hline & Zisman & 35.303 & & & & \\
\hline \multirow{5}{*}{ Triticum aestivum L. } & Acid-Base & -7.312 & 12.227 & -19.539 & -3.300 & 2.960 \\
\hline & Equation of State & 8.426 & 8.426 & & & \\
\hline & OWRK/Fowkes & 8.584 & 8.177 & 0.408 & & \\
\hline & $\mathrm{Wu}$ & 11.550 & 16.414 & -4.864 & & \\
\hline & Zisman & -12.114 & & & & \\
\hline \multirow{5}{*}{ Elymus repens } & Acid-Base & 9.146 & 8.564 & 0.583 & -1.581 & -0.184 \\
\hline & Equation of State & 5.980 & 5.980 & & & \\
\hline & OWRK/Fowkes & 9.320 & 7.433 & 1.887 & & \\
\hline & $\mathrm{Wu}$ & 8.420 & 13.115 & -4.695 & & \\
\hline & Zisman & 4.137 & & & & \\
\hline \multirow{5}{*}{ Fragaria ananassa } & Acid-Base & 28.331 & 24.502 & 3.829 & 2.345 & 0.816 \\
\hline & Equation of State & 33.340 & 33.340 & & & \\
\hline & OWRK/Fowkes & 32.908 & 27.154 & 5.754 & & \\
\hline & $\mathrm{Wu}$ & 37.372 & 28.138 & 9.235 & & \\
\hline & Zisman & 24.326 & & & & \\
\hline \multirow{5}{*}{ Vitis vinifera $\mathrm{L}$. } & Acid-Base & 19.932 & 21.289 & -1.357 & -0.579 & 1.173 \\
\hline & Equation of State & 20.888 & 20.888 & & & \\
\hline & OWRK/Fowkes & 19.990 & 19.886 & 0.105 & & \\
\hline & $\mathrm{Wu}$ & 23.407 & 23.537 & -0.130 & & \\
\hline & Zisman & 21.612 & & & & \\
\hline \multirow{5}{*}{ Cucumis sativus } & Acid-Base & 18.399 & 23.432 & -5.033 & 2.957 & -0.851 \\
\hline & Equation of State & 31.531 & 31.531 & & & \\
\hline & OWRK/Fowkes & 31.158 & 28.019 & 3.139 & & \\
\hline & $\mathrm{Wu}$ & 35.405 & 28.821 & 6.584 & & \\
\hline & Zisman & 32.160 & & & & \\
\hline \multirow{5}{*}{ Sinapis arvensis } & Acid-Base & 27.967 & 27.667 & 0.300 & 0.115 & 1.306 \\
\hline & Equation of State & 27.866 & 27.866 & & & \\
\hline & OWRK/Fowkes & 27.855 & 26.932 & 0.923 & & \\
\hline & $\mathrm{Wu}$ & 31.275 & 28.559 & 2.715 & & \\
\hline & Zisman & 30.500 & & & & \\
\hline \multirow{5}{*}{ Capsicum annuит L. } & Acid-Base & 21.274 & 30.701 & -9.427 & -1.145 & 4.116 \\
\hline & Equation of State & 30.540 & 30.540 & & & \\
\hline & OWRK/Fowkes & 29.550 & 26.182 & 3.369 & & \\
\hline & $\mathrm{Wu}$ & 33.598 & 27.505 & 6.092 & & \\
\hline & Zisman & 18.298 & & & & \\
\hline
\end{tabular}


water which has a high polar character formed the highest contact angle on the leaf surfaces. In Table 2 and Table 3, the standard deviation and standard error values of the contact angles are also given. It can be understood that the results between the data from the standard error values showing the standard deviation obtained from the same leaf surface and the variation (alteration) in the distribution of the average are close. The small standard deviation values in the contact angles also indicate the flatness and homogeneity of the surfaces.

\subsection{Surface energy measurements}

Characterization of plants through a parameter that is a combination of physicochemical properties of the leaves, will provide guiding suggestions for pesticide applications based on a condition that is created accordingly. In order to obtain an effective pesticide performance, it is required that the producers recognize the plant to which they will apply pesticide, and develop appropriate spray alternatives.

The size of the surface energy the molecular gravity that the leaf has while the droplet spreads on it in comparison with the surface tension the molecular gravity that liquid possesses is the determinant. The surface energy values obtained according to different models from the same leaf surfaces are shown in Table 4. These methods include single parameter calculations as well as surface energy values determined by two and three-component processes. Thus, different results have appeared due to different approaches in determining the leaf surface energies. In this context, more than one quantity is obtained instead of a single value describing the leaf surface. In Table 4, the fact that some results have negative values show that leaf surface tensions are less than liquid surface tensions. Also, the leaves forming low contact angles in the second level based on the Acid-Base model formed Cucumis sativus 18.399 $\mathrm{mN} \mathrm{m}^{-1}$ surface energy and the mean contact angle of $69.9^{0}$. While it was expected that a lower contact would be formed with Citrus sinensis $27.721 \mathrm{mN}$ $\mathrm{m}^{-1}$ surface energy, it has been specified that higher contact angles such as $77.2^{\circ}$ were formed. Namely, as a result, Cucumis sativus with lower surface energy spread the droplet further on its surface when compared with Citrus sinensis. Since this contradicts the definition of surface energy, it should be accepted as an erroneous approach.

In order to avoid obtaining incorrect results from data analysis, it is necessary to select the correct model and make the evaluations accordingly. In this context, when the results should be directly proportional for the conversion of contact angles to surface energy, with the exception of models the Wu's and Equation of state methods, have produced antiparallel results with the contact angles. It is understood that other methods outside these two models produce erroneous results. It has been reported in the literature that both methods give accurate results for low surface energy measurements (Wu 1973; Moy \& Neumann 1987).

In the statistical analysis for Table 3 and Table 4 carried out, Fragaria ananassa formed the first independent group as the leaves with highest surface energy from among the types of plants separated into three different groups based on their surface energies and contact angles. Cucumis Sativus, Capsicum annuum L. and Sinapis arvensis leaves with lower surface energies, produced results that can be evaluated statistically as both the first and second group. Statistically, Vitis vinifera L. leaves were ranked as the second independent group with the surface energies they possessed. Elymus repens and Triticum aestivum L. were the third group as the leaves with the lowest surface energies.

\section{Conclusions}

In Table 4, it can be observed that specified surface energy values differ based on the selected method and the fluid used. In order to make an evaluation regarding which of the numeric value(s) describe the plants correctly, the results produced by the methods should be examined based on the surface energy definitions. Determining the impact rates of the changes in spray behavior applied to an object based on the model that produces the best results will make the results more sensible. Otherwise, the analyzes to be carried out will lead to incorrect evaluations. On the other hand, it would be more appropriate to refer to a surface energy 
value range rather than a single constant value to make precise judgments based on the surface energies. The use of surface energy values with a certain numerical range instead of constant quantitative data for defining objects will be a more correct approach because of the definition of surface energy, which is not a definite case. Accordingly, the surface energies of the leaves and the application liquid surface tension value should be compared, since the application liquid with low surface tension can help droplets to more easily attach, spread and adhere to the leaf surfaces for leaves with low surface energy, it should be taken into consideration as an important factor for its use. Since the plant leaves with high surface energy will spread to the surface further, the use of liquids with higher surface tension will produce better results in preventing the leakage of the application fluid.

This research has been supported by Hakkâri University Scientific Research Projects Coordination Unit. Project Number FM2017BAP3, 2017.

\section{References}

Brewer C A, Smith W K \& Vogelmann T C (1991). Functional interaction between leaf trichomes, leaf wettability and the optical properties of water droplets. Plant, Cell \& Environment 14(9): 955-962

Fernández V, Paula G D, Peirce C A E \& Mcbeath T M (2014). Effect of wheat phosphorus status on leaf surface properties and permeability to foliar-applied phosphorus. Plant and Soil. In press. DOI:10,1007/ s11104-014-2052-6

Fowkes F M (1964). Attractive Forces at Interfaces. Industrial and Engineering Chemistry 56(12): 40-52

Hansen F K (2004). The Measurement of Surface Energy of Polymers by Means of Contact Angles of Liquids on Solid Surfaces. University of Oslo

Holloway P J (1970). Surface factors affecting the wetting of leaves. Pest Management Science 1(4): 156-163

Kaelble D H (1970). Dispersion-polar surface tension properties of organic solids. The Journal of Adhesion 2: $66-81$

Khayet M \& Ferna'ndez V (2012). Estimation of the solubility parameter of model plant surfaces and agrochemicals: a valuable tool for understanding plant surface interactions. Theoretical Biology and Medical Modelling 9(45): 1-21. DOI:10.1186/1742-4682-9-45
Krüss (2017). https://www.kruss-scientific.com/services/ education-theory/glossary/equation-of-state/ (Date of access 04.06.2017)

Li D \& Neumann A W (1992). Equation of state for interfacial tensions of solid-liquid systems. In: Advances in Colloid and Interface Science 39: 299-345

Massinon M \& Lebeau F (2012). Experimental method for the assessment of agricultural spray retention based on high-speed imaging of drop impact on a synthetic superhydrophobic surface. Biosystems Engineering 112(1): 56-64 https:/www.researchgate. net/publication/257617034_Experimental_method_ for_the_assessment_of_agricultural_spray_retention_based_on_high-speed_imaging_of_drop_impact_on_a_synthetic_superhydrophobic_surface (Date of access 08.06.2017)

Moy E \& Neumann A W (1987). Solid/Liquid interfacial tensions from contact angle data and direct force measurements. Journal of Colloid and Interface Science 119(1): 296-297

Owens D K \& Wendt R C (1969). Estimation of the surface free energy of polymers. In: Journal of Applied Polymer Science 13(8): 1741-1747

Puente D W M \& Baur P (2011). Wettability of soybean (Glycine max L.) leaves by foliar sprays with respect to developmental changes. Pest Management Science 67(7): 798-806

Rabel W (1971). Einige Aspekte der benetzungstheorie und ihre anwendung auf die untersuchung und veränderung der oberflächeneigenschaften von polymeren. Farbe und Lacke 77(10): 997-1005

Wagner P, Fürstner R, Barthlott W \& Neinhuis C (2003). Quantitative assessment to the structural basis of water repellency in natural and technical surfaces. Journal of Experimental Botany 54: 1295-1303

Wang H, Shi H, Li Y \& Wang Y (2014). The effects of leaf roughness, surface free energy and work of adhesion on leaf water drop adhesion. Plos One 9: 1-10

Wohlfahrt G, Bianchi K \& Cernusca A (2006). Leaf and stem maximum water storage capacity of herbaceous plants in a mountain meadow. Journal of Hydrology 319(1-4): 383-390

Wu S (1973). Polar and nonpolar interaction in adhesion. The Journal of Adhesion 5(1): 39-55

Zisman W A (1964). Relation of the equilibrium contact angle to liquid and solid constitution. In: F M Fowkes (Ed), Advances in Chemistry, American Chemical Society, Washington, pp. 1-51. DOI: 10.1021/ba1964-0043.ch001 